\begin{tabular}{|c|c|c|}
\hline \multirow{3}{*}{$\begin{array}{r}\text { Case Reports in } \\
\text { Gastroenterology }\end{array}$} & \multirow{2}{*}{\multicolumn{2}{|c|}{ Case Rep Gastroenterol 2014;8:251-256 }} \\
\hline & & \\
\hline & $\begin{array}{l}\text { DOI: 10.1159/000367595 } \\
\text { Published onine: August 30, } 2014\end{array}$ & $\begin{array}{l}\text { ○ } 2014 \text { S. Karger AG, Basel } \\
\text { 1662-0631/14/0082-0251 } \$ 39.50 / 0 \\
\text { www.karger.com/crg }\end{array}$ \\
\hline & \multicolumn{2}{|c|}{$\begin{array}{l}\text { This is an Open Access article licensed under the terms of the Creative Commons } \\
\text { Attribution-NonCommercial } 3.0 \text { Unported license (CC BY-NC) (www.karger.com/OA } \\
\text { license), applicable to the online version of the article only. Distribution permitted for non } \\
\text { commercial purposes only. }\end{array}$} \\
\hline
\end{tabular}

\title{
Primary Biliary Cirrhosis and Primary Sjögren's Syndrome: Insights for the Stomatologist
}

\author{
Liliane Lins ${ }^{a} c$ Raymundo Paranáa ${ }^{c} \quad$ Silvia Regina Almeida Reis ${ }^{c}$ \\ Antônio Fernando Pereira Falcão ${ }^{b}$ \\ ${ }^{a}$ Faculty of Medicine and ${ }^{b}$ Faculty of Dentistry, Federal University of Bahia, and \\ ${ }^{c}$ Bahiana School of Medicine and Public Health, Salvador, Brazil
}

\section{Key Words}

Liver cirrhosis · Primary biliary cirrhosis · Sjögren's syndrome · Oral health

\begin{abstract}
Primary biliary cirrhosis $(\mathrm{PBC})$ is a chronic progressive autoimmune disease characterized by portal inflammation and immune-mediated destruction of the intrahepatic bile ducts. Primary Sjögren's syndrome is an autoimmune disease characterized by lymphocytic infiltration of exocrine glands, mainly the lachrymal and salivary glands, in the absence of other definitively diagnosed rheumatologic disease. We report a diagnosed case of primary Sjögren's syndrome associated with PBC. A 59-year-old Caucasian woman went to oral evaluation reporting dry mouth, difficulty in eating associated with burning mouth syndrome, dysgeusia and dysphagia. Intraoral examination revealed extensive cervical caries, gingivitis, gingival retraction, angular cheilitis and atrophic tongue. Hyposalivation was detected by salivary flow and Schirmer's test was positive. Antinuclear and antimitochondrial antibodies were both positive. Anti-Ro/SSA and anti-La/SSB antibodies were negative. A minor salivary gland biopsy of the lower lip was performed. Histopathologic analysis revealed lymphocytic infiltrate with destruction of salivary gland architecture in some areas and replacement of glandular tissues by mononuclear cells. Optimal management of PBC associated with Sjögren's syndrome requires a multidisciplinary approach as the key to optimal patient care. Dental practitioners should be able to recognize the clinical features of this associated condition. Appropriate dental care may prevent tooth decay, periodontal disease and oral infections as well as improve the patient's quality of life.

(c) 2014 S. Karger AG, Basel
\end{abstract}


Lins et al.: Primary Biliary Cirrhosis and Primary Sjögren's Syndrome: Insights for the Stomatologist

\section{Introduction}

Primary biliary cirrhosis (PBC) is a chronic progressive autoimmune disease characterized by portal inflammation and immune-mediated destruction of the intrahepatic bile ducts, leading to fibrosis and liver cirrhosis [1]. Primary Sjögren's syndrome (pSS) is an autoimmune disease characterized by lymphocytic infiltration of exocrine glands, mainly the lachrymal and salivary glands, in the absence of other definitively diagnosed rheumatologic disease [2]. The involvement of non-exocrine organs such as the thyroid, kidney, heart, central/peripheral nervous system, lungs and liver has been reported in cases of pSS, liver involvement being considered a common complication in pSS [3, 4]. PBC is occasionally associated with Sjögren's syndrome and may result in liver cirrhosis. It primarily affects middle-aged women and is characterized by the presence of antimitochondrial antibodies (AMAs). Antinuclear antibodies (ANAs) and anti-smooth muscle antibody are found in about half of PBC patients and may be associated with aggressive disease and poor prognosis $[5,6]$.

We report a diagnosed case of pSS in a patient with PBC. The study protocol was approved by the Ethical Review Board of the Faculty of Medicine of Federal University of Bahia, protocol number 32559414.7.0000.5577, and is in accordance with Brazilian National Health Council Resolution 466/12.

\section{Case Report}

A 59-year-old Caucasian woman went to oral evaluation reporting dry mouth, difficulty in eating associated with burning mouth syndrome, dysgeusia, dysphagia, history of hypothyroidism and moderate pruritus. Intraoral examination revealed extensive cervical caries, gingivitis, gingival retraction, angular cheilitis and atrophic tongue (fig. 1a). Hyposalivation $(1.0 \mathrm{ml} / 15 \mathrm{~min})$ was detected by salivary flow measurement and Schirmer's test was positive $(<5 \mathrm{~mm}$ in $5 \mathrm{~min}$ ), confirming ocular involvement. Extraoral examination detected conjunctival pallor but did not reveal jaundice. Hepatomegaly and splenomegaly were absent. Panoramic radiograph examination showed generalized bone loss, presence of caries and chronic periapical lesions (fig. 1b).

The patient had a medical history of PBC and continuous treatment with ursodeoxycholic acid. In April 2013 she was admitted to a local hospital with a history of fatigue, myalgia and anorexia. Her past medical history included coronary artery disease with revascularization 15 years before. There was no history of alcohol or drug abuse. Laboratorial data revealed anemia (hemoglobin $5 \mathrm{~g} / \mathrm{dl}$; reference: 12.0-19.0 g/dl); white blood cell and blood platelet count were normal. Vitamin B12 serum level was normal and antiparietal cell antibodies were absent, excluding pernicious anemia. Liver function test showed alanine transaminase to be in the normal range, but aspartate transaminase showed a discrete increase $(57.0 \mathrm{U} / \mathrm{l}$; reference: $<36 \mathrm{U} / \mathrm{l})$. Albumin and total serum bilirubin were normal while direct serum delta bilirubin was a little increased $(0.3 \mathrm{mg} / \mathrm{dl}$; reference: 0.00 $0.2 \mathrm{mg} / \mathrm{dl}$ ). Alkaline phosphatase (342 IU/l; reference: 38-126 IU/l) as well as $\gamma$-glutamyltranspeptidase (110 IU/l; reference: 12-43 IU/l) were increased. Hepatitis B surface antigen and antibody to hepatitis $C$ virus were both negative, but hepatitis $B$ core antigen (anti-HBc IgG) was reagent. Immunoglobulin A was normal, while elevated levels of immunoglobulin M $(1,120 \mathrm{mg} / \mathrm{l}$; reference: $40-230 \mathrm{mg} / \mathrm{dl})$ and immunoglobulin $\mathrm{G}(2,557$ $\mathrm{mg} / \mathrm{dl}$; reference: $650-1,600 \mathrm{mg} / \mathrm{dl}$ ) were noted. ANAs with centromeric and cytoplasm reticular pattern were found; also, AMAs were positive (1:164 and 1:640, respectively). Antithyroid peroxidase autoantibody was negative. 
Lins et al.: Primary Biliary Cirrhosis and Primary Sjögren's Syndrome: Insights for the Stomatologist

Due to negative results of anti-Ro/SSA and anti-La/SSB antibodies, a minor salivary gland biopsy of the lower lip was performed. Histopathologic analysis revealed salivary gland acini and ducts in deeper stroma invaded by dense chronic inflammatory cells (fig. 2a). Focal lymphocytic infiltrate was observed with destruction of salivary gland architecture in some areas and replacement of glandular tissues by mononuclear cells (fig. 2b).

During follow-up, the patient presented episodes of severe anemia due to occult gastrointestinal bleeding requiring blood transfusion. Gastric and jejunal vascular ectasia were observed by endoscopy and capsule endoscopy, respectively. Then gastric antral vascular ectasia was diagnosed. The patient has been submitted to argon plasma coagulation treatment, being under close monitoring as long as she has multiple comorbidities.

\section{Discussion}

PBC was diagnosed in its early stage based on liver function tests, AMA presence in serum and histopathologic pattern of the liver biopsy. The bilirubin level in described clinical reports has indicated a good prognosis in disease follow-up with use of ursodeoxycholic acid. The simultaneous coexistence of PBC and autoimmune disease such as Sjögren's syndrome and scleroderma in PBC has been previously reported [7].

The prevalence of pSS ranges from 0.2 to $3.0 \%$ of the population, being more frequent in women (9:1 female:male ratio), aged 40-60 years $[8,9]$. The diagnosis of pSS was made according to the American-European consensus group [2]. There is no specific test for pSS and the literature presents a range of classification criteria. Many autoantibodies are associated with pSS, showing a different prevalence of specific antigens. The frequency of ANA in pSS is approximately $80 \%$ [9]. Anti-Ro/SSA and anti-La/SSB are found in 60 and $40 \%$, respectively. These autoantibodies are also seen in $30 \%$ of systemic lupus erythematosus, being not totally specific for pSS [10]. ANAs were positive in the case reported, but antiRo/SSA and anti-La/SSB were negative. ANAs are found in more than two-thirds of pSS patients, but are not disease-specific either $[8,10]$. According to the American College of Rheumatology classification criteria [11], the association of ANA and rheumatoid factor positivity may be sufficient for pSS diagnosis.

In the reported case rheumatoid factor was negative, requiring minor salivary biopsy in order to establish a diagnosis. The minor salivary gland biopsy of the lower lip evidenced a progressive focal infiltration of mononuclear lymphoid cells. Histopathologic analysis revealed salivary gland acini and ducts in deeper stroma invaded by dense chronic inflammatory cells. The present case showed many oral complications of Sjögren's syndrome such as dry mouth, difficulty in eating, tasting and swallowing associated with burning mouth, dysgeusia and dysphagia, caries, gingivitis, gingival retraction, angular cheilitis and atrophic tongue. Salivary flow reduction, detected by sialometry, may explain those conditions. Hyposalivation may lead to oral lesion such as caries, periodontal diseases and candidiasis, requiring preventive dental care in order to decrease the risk of oral infections $[12,13]$. Reduced salivary flow rates result in changes in microbial plaque composition, increasing the number and frequency of cariogenic microorganisms [12]. Other xerostomiarelated factors can contribute to caries, periodontal diseases and oral infection, such as a decrease in secretory immunoglobulin $\mathrm{A}$, lower $\mathrm{pH}$ and reduced buffer capacity, increasing time for sugar clearance [12]. An inverse relationship between salivary flow rates and Candida infection has been reported $[12,13]$. In the reported case, angular cheilitis was successfully treated with oral nystatin. 
Lins et al.: Primary Biliary Cirrhosis and Primary Sjögren's Syndrome: Insights for the Stomatologist

Xerostomia management is not well established in the literature, the use of systemic sialagogue medication showing the strongest evidence of effectiveness [13]. In the present case, the patient reported an increase in her quality of life after using salivary substitute. We opted for maintaining the use of topical salivary replacement due to the patient's comorbidities such as gastric antral vascular ectasia [14]. Adequate hydration and avoidance of potential oral mucosal irritants were recommended. The patient is under routine dental care that includes the use of fluoride preparations. In case of oral infection requiring dental surgery, as PBC may lead to liver cirrhosis, the surgeon should consider the risk of bleeding. In this particular case, the association of $\mathrm{PBC}$ with gastric antral vascular ectasia deserves concern [14]. A multidisciplinary team should evaluate the risk of presenting occult blood loss or severe upper gastrointestinal bleeding.

Optimal management of PBC associated with Sjögren's syndrome requires a multidisciplinary approach as the key to optimal patient care. Dental practitioners should be able to recognize the clinical features of these associated conditions. Appropriate dental care may prevent tooth decay, periodontal disease and oral infections as well as improve the patient's quality of life.

\section{Acknowledgements}

This work was supported by the Federal University of Bahia (grant 4244) and FAPESB/ National Council for Scientific and Technological Development (CNPq)/Brazilian Ministry of Health (grant EFP 00009556).

\section{Disclosure Statement}

No conflict of interest exists.

\section{References}

1 Jung HE, Jang JY, Jeong SW, Kim JN, Jang HY, Cho YJ, Woo SA, Lee SH, Kim SG, Cha SW, Kim YS, Cho YD, Kim HS, Kim BS: Prognostic indicators in primary biliary cirrhosis: significance of revised IAHG (International Autoimmune Hepatitis Group) score. Clin Mol Hepatol 2012;18:375-382.

-2 Vitali C, Bombardieri S, Jonsson R, Moutsopoulos HM, Alexander EL, Carsons SE, Daniels TE, Fox PC, Fox RI, Kassan SS, Pillemer SR, Talal N, Weisman MH; European Study Group on Classification Criteria for Sjögren's Syndrome: Classification criteria for Sjögren's syndrome: a revised version of the European criteria proposed by the American-European Consensus Group. Ann Rheum Dis 2002;61:554-558.

-3 Kaplan MJ, Ike RW: The liver is a common non-exocrine target in primary Sjögren's syndrome: a retrospective review. BMC Gastroenterol 2002;2:21.

4 Malladi AS, Sack KE, Shiboski SC, Shiboski CH, Baer AN, Banushree R, Dong Y, Helin P, Kirkham BW, Li M, Sugai S, Umehara H, Vivino FB, Vollenweider CF, Zhang W, Zhao Y, Greenspan JS, Daniels TE, Criswell LA: Primary Sjögren's syndrome as a systemic disease: a study of participants enrolled in an international Sjögren's syndrome registry. Arthritis Care Res (Hoboken) 2012;64:911-918.

5 Muratori P, Muratori L, Ferrari R, Cassani F, Bianchi G, Lenzi M, Rodrigo L, Linares A, Fuentes D, Bianchi FB: Characterization and clinical impact of antinuclear antibodies in primary biliary cirrhosis. Am J Gastroenterol 2003;98:431-437.

6 Invernizzi P, Podda M, Battezzati PM, Crosignani A, Zuin M, Hitchman E, Maggioni M, Meroni PL, Penner E, Wesierska-Gadek J: Autoantibodies against nuclear pore complexes are associated with more active and severe liver disease in primary biliary cirrhosis. J Hepatol 2001;34:366-372.

7 Watt FE, James OF, Jones DE: Patterns of autoimmunity in primary biliary cirrhosis patients and their families: a population-based cohort study. QJM 2004;97:397-406. 
Lins et al.: Primary Biliary Cirrhosis and Primary Sjögren's Syndrome: Insights for the Stomatologist

-8 Goëb V, Salle V, Duhaut P, Jouen F, Smail A, Ducroix JP, Tron F, Le Loët X, Vittecoq O: Clinical significance of autoantibodies recognizing Sjögren's syndrome A (SSA), SSB, calpastatin and alpha-fodrin in primary Sjögren's syndrome. Clin Exp Immunol 2007;148:281-287.

-9 Reksten TR, Jonsson MV: Sjögren's syndrome: an update on epidemiology and current insights on pathophysiology. Oral Maxillofac Surg Clin North Am 2014;26:1-12.

10 Kivity S, Arango MT, Ehrenfeld M, Tehori O, Shoenfeld Y, Anaya JM, Agmon-Levin N: Infection and autoimmunity in Sjogren's syndrome: a clinical study and comprehensive review. J Autoimmun 2014;51: $17-22$.

11 Shiboski SC, Shiboski CH, Criswell L, Baer A, Challacombe S, Lanfranchi H, Schiødt M, Umehara H, Vivino F, Zhao Y, Dong Y, Greenspan D, Heidenreich AM, Helin P, Kirkham B, Kitagawa K, Larkin G, Li M, Lietman T, Lindegaard J, McNamara N, Sack K, Shirlaw P, Sugai S, Vollenweider C, Whitcher J, Wu A, Zhang S, Zhang W, Greenspan J, Daniels T; Sjögren's International Collaborative Clinical Alliance (SICCA) Research Groups: American College of Rheumatology classification criteria for Sjögren's syndrome: a data-driven, expert consensus approach in the Sjögren's International Collaborative Clinical Alliance cohort. Arthritis Care Res (Hoboken) 2012;64:475-487.

12 Napeñas JJ, Rouleau TS: Oral complications of Sjögren's syndrome. Oral Maxillofac Surg Clin North Am 2014;26:55-62.

-13 Pinto A: Management of xerostomia and other complications of Sjögren's syndrome. Oral Maxillofac Surg Clin North Am 2014;26:63-73.

14 Nguyen H, Le C, Nguyen H: Gastric antral vascular ectasia (watermelon stomach) - an enigmatic and oftenoverlooked cause of gastrointestinal bleeding in the elderly. Perm J 2009;13:46-49.

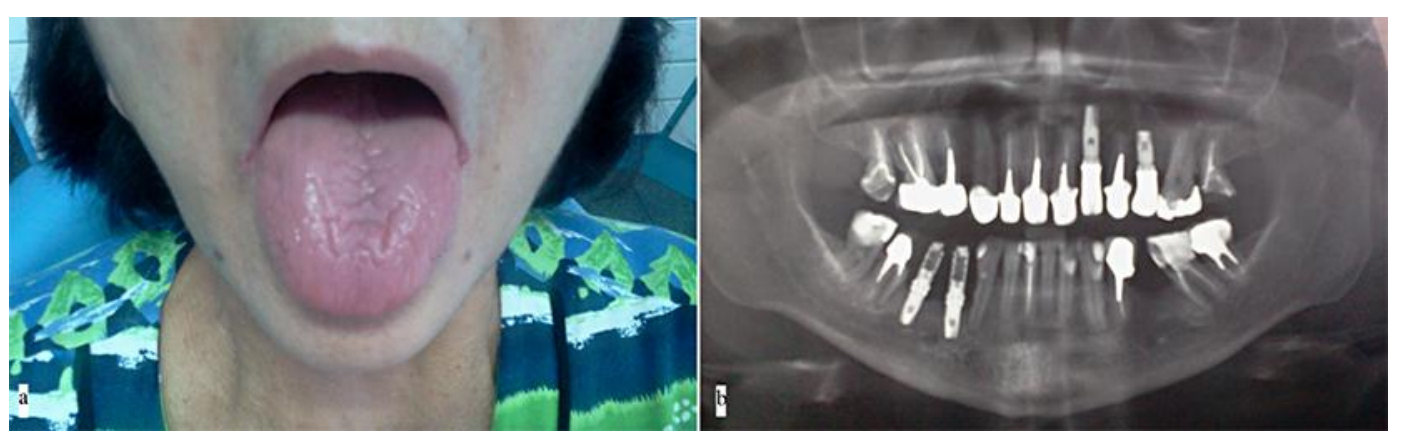

Fig. 1. a Mouth aspect at first clinical presentation. Note the severe atrophic tongue and bilateral angular cheilitis. b Panoramic radiograph taken at first clinical presentation. Note periapical lesions, caries and generalized bone loss. 


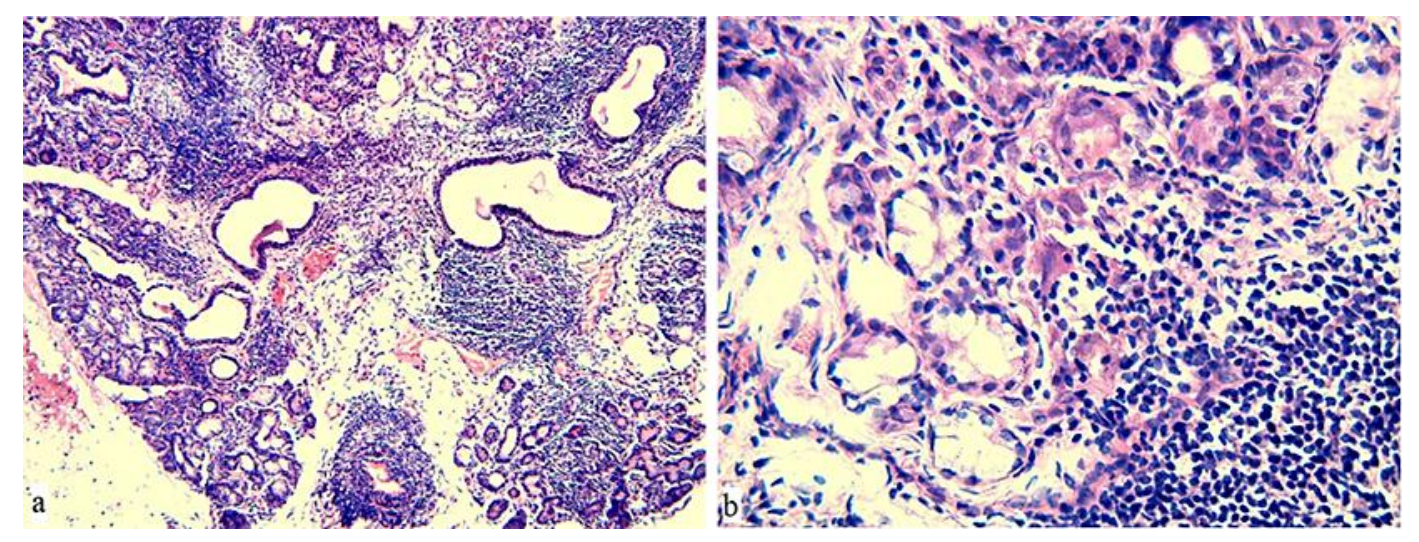

Fig. 2. a Low-power $(\times 100) \mathrm{H} \& \mathrm{E}$ histology demonstrated salivary gland acini and ducts in deeper stroma invaded by dense chronic inflammatory cells. b Higher-power $(\times 400)$ H\&E histology demonstrated focal lymphocytic infiltrate with destruction of salivary gland architecture in some areas and replacement of glandular tissues by mononuclear cells. 